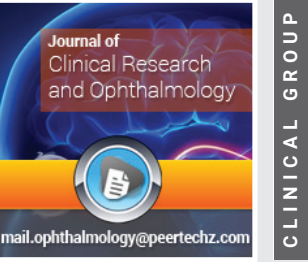

\title{
Ocular metastasis in a patient with squamous cell carcinoma tongue: A rare case
}

\author{
Nagalakshmi Narayana-Swamy ${ }^{1 *}$ and Alhaj Farhath \\ Tasneem $^{2}$
}

'PG resident, Department of Ophthalmology, Vydehi Institute of Medical Sciences and Research Center, Bangalore, India

${ }^{2}$ Professor, Department of Ophthalmology, Vydehi Institute of Medical Sciences and Research Center, Bangalore, India

Received: 16 December, 2019
Accepted: 29 January, 2020
Published: 30 January, 2020

*Corresponding author: Dr. Nagalakshmi NarayanaSwamy, PG resident, Department of Ophthalmology, Vydehi Institute of Medical Sciences and Research Center, Bangalore, India,

E-mail: anushkanarayan5@gmail.com

https://www.peertechz.com

Check for updates

\section{Introduction}

Ophthalmic metastasis from an extraocular primary malignancy is a rare event. Tongue is the most common primary site after hypo-pharynx among the oral malignancies causing distant metastasis [1].

Orbital involvement usually occurs due to direct extension of nasopharyngeal and ethmoid sinus carcinoma or through perineural invasion [2]. And the ocular metastasis especially the retina-choroid complex occurs secondary to carcinoma lung/breast [3], but ocular metastasis secondary to carcinoma tongue is a rare event. Oral squamous cell carcinoma being the $6^{\text {th }}$ most common cancer world wide [4], the treatment and prognosis of these patients is based on its distant metastasis [5].

The overall prognosis among these patients is poor. Once diagnosis has been established, treatment is essentially palliative and focused on symptomatic relief and improvement of visual function and further rehabilitation. Herein we report a case of ocular metastasis secondary to carcinoma of anterior $1 / 3^{\text {rd }}$ of tongue with disseminated secondaries.

\section{Case report}

A 42-year-old female patient was diagnosed with Squamous Cell Carcinoma (SCC) of the right side of tongue after presenting to the oncologist with small ulcerative mass since 1year. She had no history of difficulty in speech, swallowing or loss of appetite. No similar complaints in the past or no associated comorbidities.
At the patient's initial consultation in the onco-surgery clinic, physical examination revealed an ulcer proliferative growth over right lateral border of anterior one third of tongue measuring $2 \mathrm{~cm}$ from the tip, $4 \mathrm{~cm}$ away from the midline. Floor of mouth was found to be free with no extension to posterior one third. No clinically palpable neck nodes.

Magnetic resonance imaging at the time of diagnosis of primary cancer, revealed an ill-defined enhancing lesion predominantly involving the right hemi tongue, of stage T2N1MX-STAGE III and no evidence of distant metastasis. With necessary investigations patient was considered for right hemiglossectomy +extended SOHND+ left radial forearm free flap reconstruction. Intraoperative finding were found to be a mass extending from lateral incisor to first molar with multiple enlarged lymph nodes at level 1, 2 and 3. She was then subjected to 3DCRT for 1 month and discharged.

Over a span, after 6 months she presented with headache, watering and defective vision in right eye since 1week.

Her visual acuity

Right eye Counting fingers 3metres

Left eye $6 / 18$

Near vision of N36 in right eye and N12 in left eye

On automated refraction: RE showed a hypermetropic shift $(+5.00 /-1.00 \times 31)$

Colour vision: RE Red green desaturation 


\section{LE normal}

Extraocular movements with normal and full

No evidence of proptosis

The right eye appeared to be slightly low set than left eye (Figure 1)

\section{Anterior segment examination: Normal}

Fundus examination:

Right eye:

DISC: Evidence of Disc edema (Figure 2).

Superficial haemorrhages seen.

Retinal/choroidal elevated lesion.

Left Eye: Normal (Figure 3).

On a repeat CT brain and orbit revealed peripheral enhancing lesions with perilesional edema in left fronto-parietal lobe (Figure 4).

- Abnormal enhancing area around the right optic disc S/O Optic nerve infiltrations and ? orbital metastasis.

CT LUNG showed multiple heterogenous lung fields bilaterally s/o second primary or metastasis (Figures 5-8).

Patient has been referred for further radiotherapy and has been kept on follow-up (Figure 6).

Since biopsy is not recommended for such type of ocular metastasis, we are not certain about the histopathological feature of this ocular metastasis and evidence of the origin of this tumour from primary squamous cell tumour (Figure 7).

Patient was referred for radiation therapy and is on treatment and kept on followup (Figure 8).

\section{Discussion}

Ocular metastasis occurring is a rare entity. Among study conducted by Shields [6], studied on 1274 patients suggested only $7 \%$ of the patient had metastatic tumours and also isolated metastasis to the eye is quiet rare [7], compared to other sites.

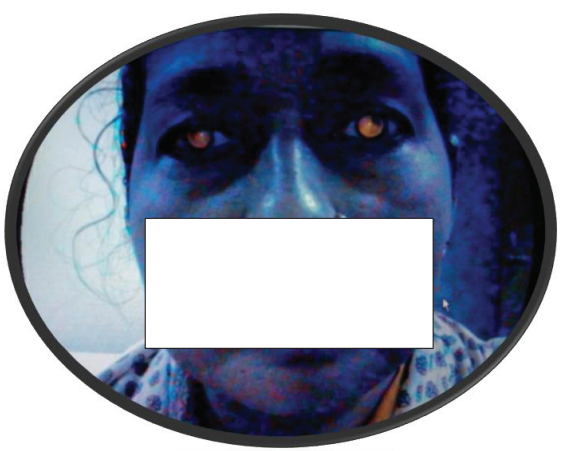

Figure 1: Image of the patient showing slightly lower set right eye and normal fundal glow.

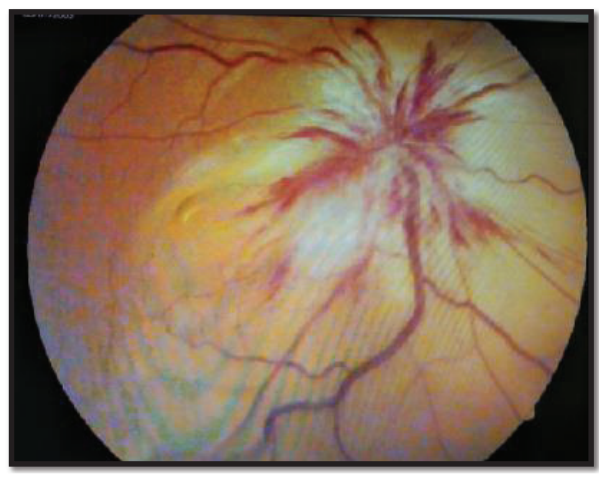

Figure 2: Fundus imaging showing disc edema.

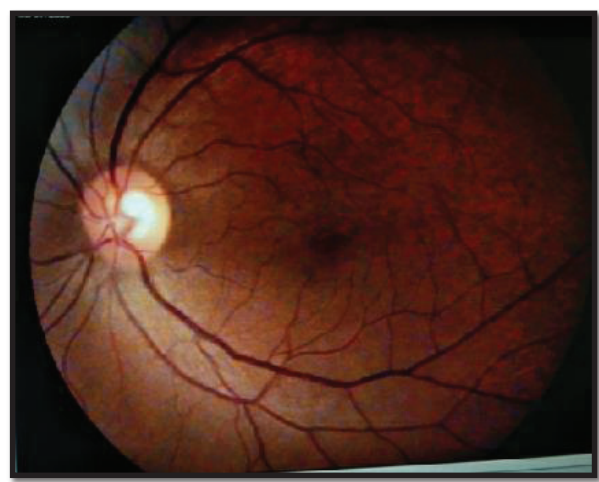

Figure 3: Fundus image showing normal disc and macula.

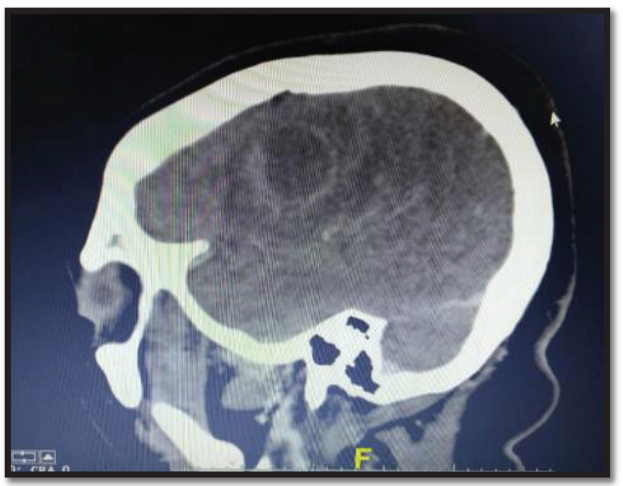

Figure 4: Computerised tomography showing a peripheral ring enhancing lesion suggestive of metastasis.

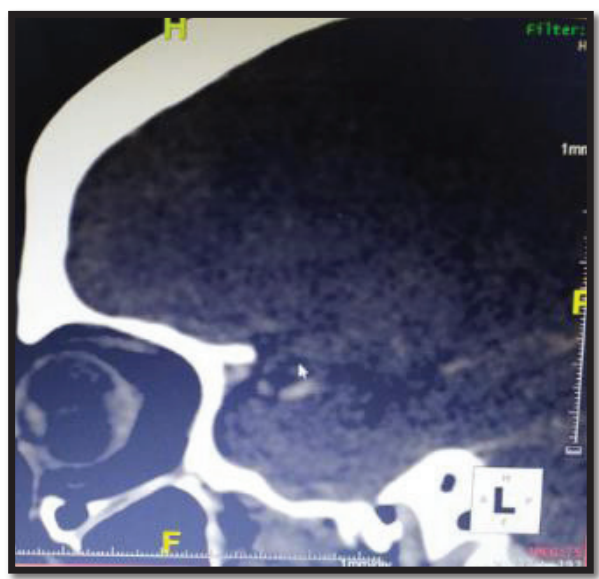

Figure 5: CT Image showing optic nerve head involvement

Citation: Swamy NN, Tasneem AF (2020) Ocular metastasis in a patient with squamous cell carcinoma tongue: A rare case. J Clin Res Ophthalmol 7(1): 001-003. DOI: https://dx.doi.org/10.17352/2455-1414.000062 


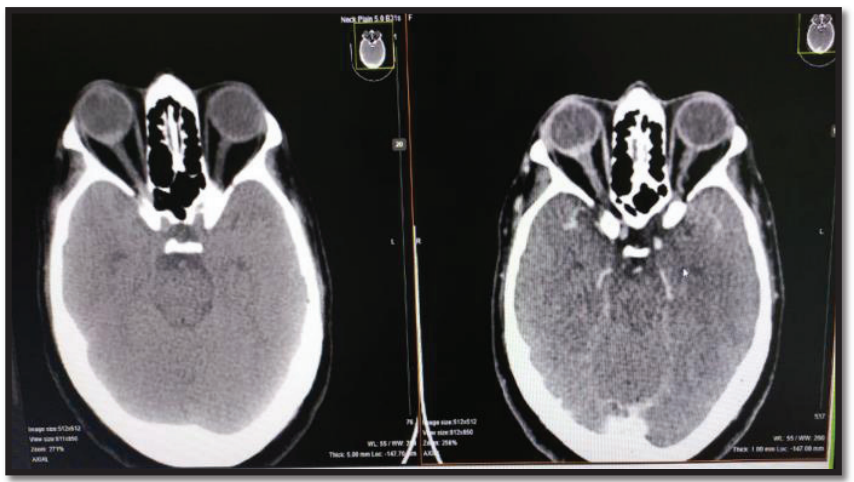

Figure 6: CT image showing hyper echoic optic nerve head s/o infiltration.

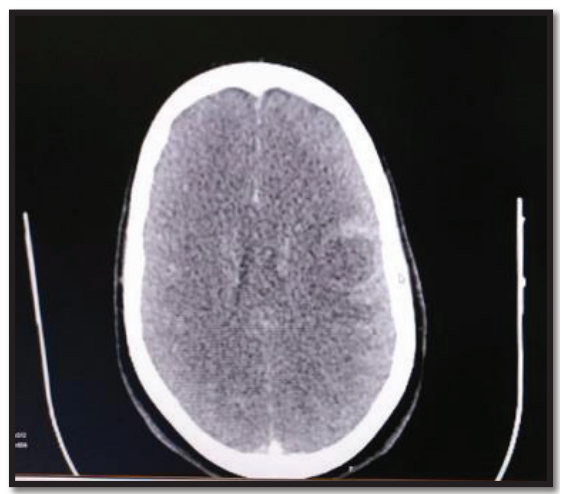

Figure 7: CT Brain showing peripheral enhancing lesion.

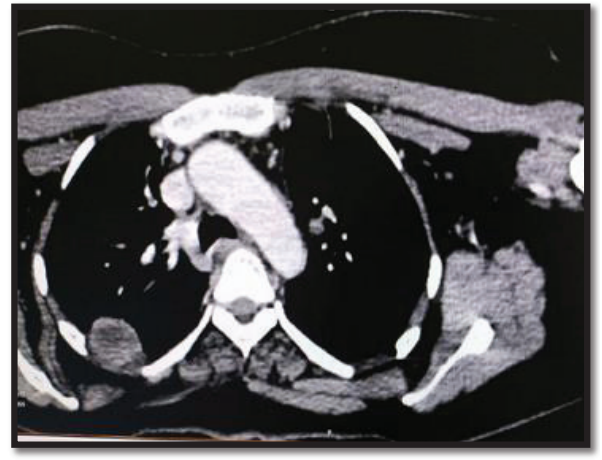

Figure 8: CT Lung showing metastatic deposits and lymphadenopathy s/o lung metastasis.

The most common tumours metastasising to the orbit are breast, lung, genitourinary tract and gastrointestinal tract [8]. The possible explanation for this phenomenon could be restricted orbital volume with limits the extent of the mass and thus appearance of late symptoms. Unilateral metastasis is common than bilateral metastasis [9], some studies have indicated that metastatic disease is more common in the left orbit because the left carotids ascends directly to the aorta.
However, in our study the patient had primary carcinoma of tongue that presented with the ocular and orbital metastasis of which very few cases have been reported [10].

The treatment for orbital metastasis is palliative. The major goals of the treatment are to improve the patient's quality of life and preserve visual function. Surgery is no role and be associated with significant ocular morbidity. Radiotherapy may alleviate symptoms in majority of the cases and may be able to restore some degree of vision. Patient's general health, life expectancy and side effect of treatment must be taken into account.

Thus, accurate and early screening among these patients with occult metastases is recommended. The need for further evidence to understand the pathogenesis ,awareness of the condition among the clinician's and a possibility of eye screening in patients with carcinoma tongue for a better visual rehabilitation may aid in palliation among these patients is required.

\section{References}

1. Kotwall C, Sako K, Razack MS, Rao U, Bakamjian V, et al. (1987) Metastatic patterns in squamous cell cancer of the head and neck. Am J Surg 154: 439442. Link: http://bit.ly/2Rz6Crc

2. Samanta DR, Bose C, Bhuyan R, Mishra SR, Senapati SN (2015) Ophthalmic Metastasis in Squamous Cell Carcinoma of Head and Neck: A Study on Two Patients. Int J Sci Stud 3: 230-233. Link: http://bit.ly/3aPvQJr

3. Font RL, Ferry AP (1976) Carcinoma metastatic to the eye and orbit III. A clinicopathologic study of 28 cases metastatic to the orbit. Cancer 38: 1326 1335. Link: http://bit.ly/2RA4fUU

4. Parkin DM, Bray F, Ferlay J, Pisani P (2005) Global cancer statistics. Cancer J Clin 55: 74-108. Link: http://bit.ly/38RNR8m

5. Takes RP, Rinaldo A, Silver CE, Haigentz M, Woolgar JA, et al. (2012) distant metastases from head and neck squamous cell carcinoma. Part I. Basic aspects. Oral Oncol 48: 775-779. Link: http://bit.ly/2tZhnKo

6. Shields JA, Shields CL, Scartozzi R (2004) Survey of 1264 patients with orbital tumours and simulating lesions. Ophthalmology 111: 997-1008. Link: http://bit.ly/20a4ZhD

7. Ferry AP, Font RL (1974) Carcinoma metastatic to the eye and orbit. A clinicopathologic study of 227 cases. Arch Ophthalmol 92: 276-286. Link: http://bit.ly/2vxrQ03

8. Backhouse O. Simmons I. Frank A,Cassels Brown A (1998) Optic nerve breast metastasis mimicking meningioma. Aus N Z J Ophthalmol 26: 247-249. Link: http://bit.ly/3aQRMUz

9. Ahmad SM, Esmaeli B (2007) Metastatic tumours of the orbit and ocular adnexa. Curr Opin Ophthalmol 18: 405-413. Link: http://bit.ly/37CRU8a

10. Marioni G, Doro D, Marino F, Verdecchia P, Staffieri C et al. (2003) Skin and Eye: Uncommon Sites of Distant Metastasis from Tongue Base Squamous Cell Carcinoma. Acta Oto-Laryngologica 123: 1110-1114. Link: http://bit.ly/2GzFFOk

Copyright: (c) 2020 Swamy NN, et al. This is an open-access article distributed under the terms of the Creative Commons Attribution License, which permits unrestricted use, distribution, and reproduction in any medium, provided the original author and source are credited. 